\title{
A new era for the Journal of Medical Microbiology
}

This issue, January 1996 (volume 44, issue 1), marks a new era for the Journal of Medical Microbiology. Regular subscribers will have noticed immediately the change from dull green to brilliant red for the cover, and possibly also the new publisher's logo. This is the first issue published under the new agreement between The Pathological Society of Great Britain and Ireland and Chapman \& Hall - the first of what we hope will be a long and scientifically progressive association.

There are also some changes within the new covers not too dramatic because the Journal of Medical Microbiology has a sound reputation for publishing high quality articles, but building upon the traditional strengths of the Journal and bringing forward new forms of contribution of value to our readership. Changes in style and content of the Journal have been introduced gradually over recent years; the new appearance gives us the opportunity to consolidate them into a composite package providing what both readers and contributors require.

The core element of any primary journal is the original scientific articles submitted for peer review and publication by active research workers. This remains the major function of the Journal of Medical Microbiology - to provide a forum for the dissemination of scientific research. The scope of the Journal is wide, encompassing not only the human medical microbiology indicated by the title, but also dental and veterinary microbiology, and including all types of micro-organisms that come within the term microbiology - bacteria, viruses, fungi, protozoa and even some helminths. This range of material has been emphasised during the past two years by the use of section headings - bacterial/viral pathogenicity, antimicrobial agents, epidemiological typing, medical mycology, clinical infections, and so on; this has proved to be very popular with readers and will be retained. However, many medical, dental and veterinary microbiologists are diagnostic and therapeutic practitioners rather than fully committed research workers. They want to see the latest research findings but they also need to enhance their knowledge across the broad field of microbiology and to maintain their continuing medical/professional education (CME/CPE). For the last six to seven years we have included a range of occasional review articles providing in-depth commentary on particular topics in microbiology. These have ranged from detailed single-author reviews to multi-author composite articles based upon symposia held during various scientific meetings and congresses. They have been a popular component of the Journal and we plan to establish a consistent flow of such reviews to sustain a publication rate of at least one per monthly issue. More recently, over the last three years, we haye introduced a regular editorial - a short but expert commentary on a current area of debate or interest in medical microbiology. These have also proved popular and will be continued at a rate of one or more per month. Both reviews and editorials are approved as vehicles for $\mathrm{CME} / \mathrm{CPE}$ by the Royal College of Pathologists.

Readers who have followed the Journal since the 1970 s will remember that 'short articles' used to form a regular part of the contents list. This section was dropped during the 1980 s because it became increasingly difficult for the editors to distinguish between short substantial papers and brief reports, and all became 'papers'. It is now clear to the editors that there is a need for three types of short article: brief reports of technical methods, commentaries based upon interesting and uncommon cases, and preliminary reports of interesting findings. All three types of article will be welcome and will be accomodated in sections of the Journal devoted to 'short articles' or 'technical notes'. These brief communications will be restricted to c. 1500 words in length, generally with only a single table or figure and no more than 12-15 reference citations. The current sections providing book reviews and announcements of national and international meetings concerning medical microbiology and infectious diseases will continue.

In addition to these sections, a major innovation for the Journal in 1996 will be the creation of a correspondence section for 'letters to the editor'. This section is intended to provoke scientific debate about material published recently in the Journal and about contemporary issues in medical/dental/veterinary microbiology. It is not intended to be a vehicle for informal publication of new experimental data but will give microbiologists the opportunity to challenge and debate published material and to raise matters of general interest. Letters should be sent to the Editor at The 
Pathological Society of Great Britain and Ireland, 2 Carlton House Terrace, London SW1Y 5AF. Editors will reserve the right to decide whether publication is appropriate and will also give the original authors of a hypothesis or set of results the opportunity to respond. These are important developments for an established journal that will enhance its position at the centre of research and debate in medical microbiology.

As indicated on the front cover and title page, the Journal title and copyright are owned by the Pathological Society. The Society was formed in 1906 to provide a forum for scientific debate and the presentation of research results in the various areas of pathology - the primary sections of the Society being histopathology and medical microbiology. As well as representing pathologists in the UK and abroad, the Society includes around 240 microbiologists in its membership. The Microbiology Division is very active and is responsible for part of the organisation of the summer and winter meetings of the Society. On each occasion two half-day symposia with international speakers as well as original paper sessions (both oral presentations and poster displays) on microbiology are included in the programme. Attendance at Society meetings is open to all. There is a modest daily registration fee.

The Society is a registered charity. Its main scientific and educational activities are the scientific meetings and the publication of three journals. The titles and copyright of the Journal of Pathology and the Journal of Medical Microbiology belong to the Society and Reviews in Medical Microbiology, although owned by the publishers (Chapman \& Hall) is published as a journal of the Society.

The journals are both educational and commercial ventures. The profits earned by the Society from the journals are used to support the scientific disciplines of medical microbiology and pathology. As well as subsidising the winter and summer meetings, the Society's income is fed back into the development of the science itself, principally by grants to young medical scientists and by supporting other scientific meetings in specialised fields of microbiology and pathology. For the past decade the Society has awarded a series of vacation/elective scholarships to enable medical students with an interest in laboratory medicine to gain some first-hand experience in a microbiology/pathology laboratory in the UK or abroad, usually linked to a short research project that may set the student on a career in medical research. The Society also recognises the value of intercalated BSc degree courses for the inspiration of medical students who may subsequently make their career in laboratory medicine and contribute to the development of microbiology and pathology. The Editor-in-chief of this journal is only one of many who learnt the fascination of medical science by this route. From
1991 to 1994 the Society awarded three scholarships each year to enable medical students to take a year off from their medical studies to undertake a BSc course and this became four per year in 1995; this is the seedcorn of our disciplines for the future.

Young post-graduate medical scientists also need support and the Society funds two schemes aimed at training in medical scientific research. Since 1987 it has given travelling fellowships to enable young microbiologists and pathologists to spend time visiting laboratories other than their own and, in particular, to learn new techniques and approaches. These fellowships are now complemented by a second form of support - a Pathological Society PhD studentship to be awarded annually for a three year programme of research in one of the branches of pathology.

The Society also supports scientific meetings of other smaller groups and one of its aims is to develop stronger links with similar societies in Europe. Currently, reciprocal arrangements are being discussed with the Dutch Medical Microbiology Association and the Hungarian Society of Microbiology. The Microbiology Division has also joined the Federation of Infection Societies, a group of six societies with a common interest in infection, who hold conjoint meetings at regular intervals. It is our desire to raise the profile of medical microbiology and we are actively seeking new members to join the Pathological Society.

In these ways the commercial success of the journals and the efforts of the editors are channelled back into the scientific activities that are the heart of the disciplines of microbiology and pathology and which themselves underpin the whole of medicine, dentistry and veterinary medicine.

Membership of the Society is open to all involved with and interested in' pathology in all its forms; members receive individual copies of the journals at much reduced rates. For further information, please contact:

\section{Mrs J. Edwards \\ Pathological Society of Great Britain and Ireland \\ 2 Carlton House Terrace \\ London SW1Y 5AF \\ Tel: +44 (0)171976 1260 \\ Fax: +44(0)171976 1267}

The editors of the Journal of Medical Microbiology hope that the readers and contributors will be equally enthusiastic about the developments in the 'new' journal so that it will continue to go from strength to strength.

BRIAN I. DUERDEN

Editor-in-chief 